\title{
LO QUE FUE PRESENTE: UN DIARIO A CORAZÓN ABIERTO*
}

\author{
LO QUE FUE PRESENTE: \\ an Open-Heart Diary
}

Augusto Escobar Mesa ${ }^{1}$

\footnotetext{
* Cómo citar esta conferencia: Escobar Mesa, A. (2021). Lo que fue presente: un diario a corazón abierto. Estudios de Literatura Colombiana 49, pp. 233-241. DOI: https:// doi.org/10.17533/udea.elc.n49a13

\section{1 https://orcid.org/0000-0001-9410-9151 aescobar1974@yahoo.es \\ Université de Montréal, Canada}

Editores: Andrés Vergara Aguirre, Christian Benavides Martínez

Recibido: 13.05 .2021

Aprobado: 21.05.2021

Publicado: 30.06 .2021

Copyright: (2021 Estudios de Literatura Colombiana. Este es un artículo de acceso abierto distribuido bajo los términos de la Licencia Creative Commons AtribuciónNo comercial - Compartir igual 4.0 Internacional

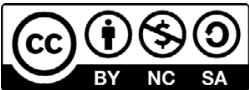

Cuando en una época estuve en el apartamento de Abad trabajando en una bibliografía sobre su obra, recuerdo haber visto muchas libretas y agendas de distintos formatos, colores y diseños en las que en esas mismas iba consignando todo cuanto iba padeciendo en la vida con sus logros y miserias, dudas y contradicciones, que eran tantas que apenas si le dejaban respirar, pero gracias a esa época de incertidumbres, un libro tras otro fue gestándose. Y ahí está la paradoja del Diario: deuda con los que le afligieron la vida y con los que, por inmadurez — todo lo contrario a la mala fe-, se las amargó. Hoy los lectores conocen esos avatares: ¡una vida bien vivida como si fuera una tragicomedia y gran teatro de aciertos y desvaríos! Pero hay otra enorme deuda revelada en su Diario y es con todos esos buenos y malos escritores que leyó buscando zafarse de ellos para encontrar el camino que le llevara a sí mismo.

Lo que fue presente (Abad Faciolince, 2019) es pues la confesión de diversas lecturas de una misma vida vivida con un doble afán, no morirse en el intento antes de ser alguien, es decir, un escritor distinto, y ver a sus hijos llegar a adultos buscando 
realizar sus sueños. Son veinte años ininterrumpidos, 1985-2006, de estar anclado en un presente que deja un sabor amargo porque los titubeos, las culpas y resentimientos acosan como jauría en celo. Los 27 años, cumplidos en 1985, marcan el inicio del Diario de Abad cuando la juventud se ha ido y todo aun es incierto, porque no hay terminado unos estudios en forma, no tiene una relación única, no sabe lo que quiere realmente, aunque el zumbido de escritor va y viene. Lo único que percibe en el horizonte es una encrucijada de caminos, ninguno con salida, pero esa lejanía informe será su propio desafío y motivo de desazón permanente.

Tres cosas fundamentales cubren el universo de expectativas en Abad en su Diario: la muerte violenta del padre en 1987 que deja a un hijo a la deriva en busca de un padre totémico; el nacimiento de sus dos hijos, Daniela y Simón, y un sueño, ser escritor. La primera cosa lo marcará para siempre por la violencia irracional en un país que Abad ama y odia. Colombia es para él el ámbito de todos los excesos y no da tregua para que el respeto del otro tenga asidero, debido a la ambición desmedida de unas minorías poderosas y fundamentalistas que azuzan a otras minorías fanáticas y violentas para que realicen de facto lo que ellos desean, eliminar por cualquier medio a los que piensan distinto y buscan el bien de las mayorías, como fue la voluntad indesmayable de su padre, un humanista a tiempo cabal. Y al lado de estas minorías conviven grandes sectores de la sociedad que apenas si sobreviven porque han sido excluidas de casi todo, salvo la mano de obra barata.

El Diario muestra de muchas maneras cómo esa pandemia de la violencia en todas sus formas se ha incubado en la historia colombiana y no pareciera vislumbrar otro derrotero. La segunda cosa que sostiene emocionalmente a Abad es el nacimiento de sus dos hijos, porque ellos son el condominio del amor y de su preocupación desmedida. En el Diario los vemos crecer, igual que su padre que desborda de afecto y se desvive por ellos. Son ambos un pequeño oasis de paz y de felicidad; su lenitivo y talón de Aquiles que lo fragiliza aún más por lo que les pueda pasar. En fin, ellos son su amor. El amor por ellos es réplica pálida del amor buscado a través de otras mujeres que han cruzado su vida y le han permitido ir descubriendo a tientas esas almas gemelas, abanico de luces y sombras, de misterios y epifanías. Estos dos baluartes fundamentales, su padre ausente y sus hijos, acentúan su valor y se vuelven aún más significativos cuando su proyecto de vida de ser escritor va construyéndose. De esta manera se realiza uno de los anhelos de su padre que creía ciegamente en ese destino 
del hijo. En Abad-hijo, ser escritor y vivir del oficio es también cumplirles a los hijos, porque quiere brindarles un futuro sin apremios y fijar una raíz de la cual puedan estar orgullosos. De ese pasado incierto de los ochenta hasta el presente con expectativas, Abad puede darse por satisfecho porque con aciertos y reveses, todo lo que ha querido lo ha podido llevar a cabo: escritor, cronista, periodista, editor de una revista, director de una biblioteca universitaria y de su propia editorial, traductor, librero, columnista. Y, desde estos múltiples oficios, ningún género le ha sido ajeno: novela, cuento, ensayo, crónica periodística, poesía, diario, crónica de viajes y hasta un género indefinido o recetario como lo es su Tratado de culinaria para mujeres tristes (1996).

La fecha de corte del Diario es 2006, decisión tomada por su editor, pero también porque es un momento significativo para Abad al publicar su obra más apreciada por los lectores y reconocida por la crítica, El olvido que seremos. Con esta obra se catapulta y logra el objetivo tan anhelado, ser reconocido como escritor y leído no solo en su país, sino en otras partes. Al margen de las novelas de García Márquez, El olvido que seremos ha sido la obra más leída por los lectores más diversos y la que más reediciones ha tenido. Con ella, sin duda, Abad reivindica lo que deseaba su padre y el voto de confianza que este siempre tuvo en su hijo de que en el futuro sería valorado. También es una fecha de cierre necesaria, porque hasta ese momento Abad ya había publicado cuatro novelas, Asuntos de un bidalgo disoluto (1994), Fragmentos de amor furtivo (1998), Basura (2000) y Angosta (2004), que considera su mejor obra. También había incursionado con un libro de relatos, Malos pensamientos (1991); un libro de ensayos, Palabras sueltas (2002), y una crónica de viajes, Oriente empieza en El Cairo (2002); es decir, ya había publicado lo mejor de su producción literaria. Con lo alcanzado con El olvido que seremos y su amada Angosta, Abad ya puede apropiarse de los versos del poema “¡Oh capitán, mi capitán!” de Whitman: “¡Oh capitán, mi capitán! / Terminó nuestro espantoso viaje, / El navío ha salvado todos los escollos, / Hemos ganado el codiciado premio, / Ya llegamos a puerto, ya oigo las campanas, / Ya el pueblo acude gozoso".

En Lo que fue presente se impone una evidencia desde la primera página hasta la última y es la duda, no la cartesiana sobre sí mismo, sino la visceral que aguijona su existencia y único deseo, ser escritor. Por doquier, preguntas inquisitivas van y vienen y lo acompañan como sombras detrás de cada uno de sus actos, gestos y oficios porque no tiene convicción de nada, pero sí de una imagen disolutiva que lo acecha 
y se cuela por todos los intersticios de su vida. Abordar el Diario de Abad es emprender un viaje, no por el país de las maravillas de Alicia, sino por una encrucijada de caminos inciertos que se van perfilando a medida que va asumiendo los desafíos necesarios para sobrevivir. Es un viaje sin retorno por tres vidas, la privada que toca a veces los límites de la vida íntima y secreta, y estas terminan volviéndose cosa pública para un lector invitado y con el derecho a entrometerse en su vida. Porque eso es el Diario: una invitación a una aventura voyerista por esas múltiples vidas. El lector tiene permiso para fisgonear por los intríngulis de un ser asido siempre a una cuerda floja de la que, a menudo, piensa no podrá liberarse para alcanzar puerto seguro. La de Abad es la vida de alguien que se balancea al borde de un abismo y donde resuena el eco de una voz vacía porque toda certidumbre le es ajena. Él es apenas "el eco de una sombra”, suma de ambigüedades y remordimientos que lo punzan por doquier.

En la novela La oculta hay un pasaje en el que describe un lago que está al pie de la casa de una hacienda de unos primos de Abad, ubicada en un flanco de la cordillera occidental en el suroeste antioqueño. Es un lago, oscuro por su profundidad, en el cual el protagonista solía nadar y donde varias personas se habían ahogado antes, entre ellos “un poeta Nadaísta y mal nadador, Amílcar Osorio”. Un día un visitante cae en el lago y Abad se lanza en su búsqueda para salvarlo, pero resulta en vano por la profundidad y oscuridad del agua. Este hecho nos sirve metafóricamente para mostrar cómo era la vida de Abad antes de la muerte de su padre: nadar por puro placer porque la vida era un fluir casi bucólico, sin preocupaciones económicas, sin sobresaltos, porque todo lo tenía satisfecho con su padre-madre-protector o, más bien, el Abad-hijo no sabía qué hacer precisamente por las condiciones anteriores, por eso había empezado y abandonado dos carreras, acompañado temporalmente a su padre en un puesto diplomático en México para dedicarse a lo que sí le gustaba: leer, asistir a talleres de literatura, divertirse y nada más. El amor por una italiana a la que le sigue los pasos lo lleva a Turín, en donde inicia y termina los estudios de literatura y se hace lector, cargo privilegiado para estudiantes singulares. En esos devaneos de desbrozar y encontrar un sendero a seguir llega su primera hija sin pedir permiso, y todo esto hace que la vida se imponga por fin con su aplastante realidad. No es ya un nadar por encima y por placer, sino un bucear sin saber qué le espera en esas aguas oscuras y gélidas. Estos hechos y otros colaterales dan inicio al Diario que se vuelve una necesidad para resistir, sobre todo ante la inesperada muerte de su padre, llevada a cabo por vo- 
luntad de unos energúmenos con poder que odian irracionalmente a los que no se les parecen. Abad-hijo se zambulle en ese hoyo negro de La Oculta, y por más que busca a ese ser que debe rescatar de la sombría parca, el frágil hilo que ata al hijo del padre se ha vuelto añicos. Los abanderados de la muerte han impuesto su ley y Abad-hijo queda de nuevo a la deriva. Es ahí cuando todo se rompe y fragiliza aún más la condición del joven Abab, porque - como lo expresa el lamento desesperado de uno de los personajes del cuento “¡Diles que no me maten!”- “Es algo difícil crecer sabiendo que la cosa de donde podemos agarrarnos para enraizar está muerta” (Rulfo, 2005, p. 96).

Como en un fundido encadenado, ese padre ausente se fusiona con la imagen del poeta muerto al que se traga ese lago sombrío que nadie puede recuperar, porque en su interior hay corrientes subterráneas, algas asfixiantes, fuerzas oscuras que medran tras bambalinas. Por más que se intenta prevenir del peligro de esos lagos engullidores, el padre y el poeta hacen caso omiso porque piensan que son inocuos los peligros que se anuncian. Un destino irremediable se impone, misma fatalidad que pesa en adelante sobre Abad-hijo como el peor de los fardos por no haber podido salvar a ese padre y al poeta. Serán veinte años de espera y de rumiar para medio liberarse de esa rémora de culpas con El olvido que seremos, que no es otra cosa que una suma de confesiones, testimonios y, a la vez, bálsamo reparador. El Diario tiene ese efecto, entrar en un lago oscuro y revuelto tras un muerto (el padre) y la muerte en vida (el hijo) sin que en el fondo nada pueda distinguirse. Ese pozo de agua en el que se ha caído parece devorarlo todo, no deja respirar y menos ver con claridad. Y es ahí cuando comienza la lucha desesperada por Ver lo que no se deja ver. Es un nadar arduo para desbrozar un camino de algas espinosas que atrapan y sofocan. Es la noche oscura que parece no anunciar la aurora, pero es en ese esfuerzo sobrehumano que se va imponiendo una voluntad de poder para salir adelante, para ir buscando pequeños haces de luz en medio de las tinieblas y orientarse hacia la superficie para volver a respirar y recuperar la vida. Y esos haces de luz es la escritura misma, el poder definitivo de la palabra que va cicatrizando las heridas, despojando de tanto lastre y, en definitiva, redimiendo porque deja Ver lo que estaba enmarañado. Bajo estas circunstancias, la palabra hecha verbo y escritura es un dejar vida libre a la "avidez de la mirada y el deseo de describir lo que se ve y se vive con intensidad”(Miłosz, 1990, p. 248).

Aunque Abad confiese hoy su agnosticismo, no puede liberarse de la formación católica en el seno de su familia y durante los estudios colegiales. Es algo que lleva 
como un estigma, y lo llevamos todos los que padecimos ese mismo flagelo ideológico. Incluso los grandes pensadores y escritores ateos pasaron parte de su vida escribiendo y peleando contra ese fardo mental, pero nunca pudieron ser ajenos a ese signo cainita incrustado en el fondo de la conciencia de los occidentales. Abad porta doble peso, el de una devota familia materna, incluyendo obispos en su haber, y sus estudios secundarios en una institución del Opus Dei. Comunidad esta poderosa, hermética, jerárquica e ideologizaste que se impone en los adeptos de clase, de grupo, de familia en todos sus actos y gestos por mínimos que ellos sean. Como en el ritual cotidiano de los incondicionales del Opus Dei que se levantan y acuestan reconociéndose pecadores hasta la médula y deben "reparar los pecados propios y los ajenos" y, de esa manera, contribuir a "desagraviar al Señor", el Diario es la imagen del confesionario al que Abad se aproxima compungido, abre la ventana del arrepentimiento y comienza una confesión sin tapujos, sin temor a enfrentar tantas verdades que solo él conoce. Es un pecador arrepentido que debe exponerse al escarnio público, porque solo mediante esa humillación y dolor puede alcanzar una redención temporal, nunca definitiva.

Lo que fue presente es precisamente eso, un desnudarse ante los lectores que están al otro lado de la ventana enrejada del confesionario oyendo esa alma desgarrada, intimidada, vuelta añicos y vacía, porque no se imaginan que ese ser exitoso en lo exterior lleva tal procesión por dentro. Los lectores viven en presente ese estado de ascesis en la que el Abad-hijo entra en esa noche oscura cuasi mística que le arranca gemidos de dolor y se autolapida como Job y lamenta como Jeremías por haberle hecho mal a su primera esposa, a sus hijos, a sus amigos y a otras mujeres, y en algunos momentos,incluso a los lectores que lo han seguido, por no haber estado a la altura de sus expectativas. El Diario se inicia pues con una confesión, sigue con el mismo tono y termina igual, pero ya arrepentido de tantas culpas cometidas y consolado, porque ha cumplido por lo menos la promesa más importante a su padre que este no alcanzó a ver realizada: ser un escritor y haber logrado el reconocimiento de los suyos, de los lectores y hacer inolvidable la imagen de un Padre que intentó siempre que su vida y la de los suyos fueran "una obra de arte".

Decidirse a publicar el Diario implicaba para Abad dos cosas: enfrentarse a los lectores para ser juzgado como un chivo expiatorio, tener compasión de ese ser victimizado y exorcizar un nuevo fracaso, una novela impublicable. Ambas decisiones eran heridas abiertas que había que asumir, y así fue. Ser escritor le ha costado 
a Abad-hijo muchos años de rasgarse las vestiduras en silencio y flagelarse como lo manda el rezago ideológico opusdeiano. Tal como lo sugiere Paul Ricœur y lo percibimos en el Diario, mientras el pecado es una situación objetiva por ser una realidad colectiva en la cual toda una comunidad de creyentes está implicada, la culpa es algo subjetivo, es un estado de interioridad en el que la conciencia individual "se siente abrumada por un peso que aplasta” y un remordimiento que roe desde dentro. El sentimiento de culpa del narrador opera pues como un "tribunal invisible que mide la ofensa, pronuncia la condenación e inflige el castigo" (Ricœur, 1969, p. 419). En este sentido, el Diario es una doble confesión: la primera, hacia adentro, en secreto, protegida de toda injerencia exterior, y ahí la voluntad individual se impone durante más de veinte años; pero esta confesión es incompleta sin la segunda, en la que debe revelar a los demás, en 2019, esa condición mísera por haberse mostrado egoísta, arrogante y prepotente, y por haber pisoteado la dignidad de seres queridos. $\mathrm{Y}$ para eso se necesita masoquismo y mucho coraje, porque rara vez, en Colombia sería la primera, un escritor es capaz de enfrentar a su entorno familiar, amigos y lectores con las autodefensas bajas y sin otro ánimo que invocar la compasión, la solidaridad y el respeto de ser un simple humano hasta los tuétanos. Lo que fue presente es sin duda una confesión a corazón abierto.

El eje nucleador del Diario es pues la puesta en evidencia de un oficio y los desafíos que implica, ya que enfrentarse a la hoja en blanco es para el escritor algo tan esencial y frustrante como la vida misma, porque es vacío y expectativa. Pero mejor dejemos que Abad mismo lo diga con sus propias palabras:

Para mí, la escritura es como tirarme de noche en un lago; yo voy nadando, a veces debajo del agua, a veces por fuera, pero no tengo muy claro ni dónde está la otra orilla ni para dónde voy [...] No sé si seré capaz, de qué seré capaz. Hay un fondo de mí lleno de nada, tal vez estoy vacío, inexorablemente. Soy un hueco coco, vacío, donde resuena el eco de un vacío sin voz, el eco de una sombra. Dentro de mí la más oscura oscuridad. Triste, negra, ciega. Me duele no poder ser el escritor que quise ser, es horrible postergar diariamente mi compromiso con las palabras. Esta rápida improvisación de ideas inconexas no vale la pena. Es un burladero en la mitad del ruedo, una forma de no enfrentar las astas (Martín, 2020).

Si la vida es un aprendizaje de nunca acabar y siempre comenzar, más es el oficio de atrapar las palabras para que ellas hablen con su propia voz. Ante esta ardua tarea nunca se llega a la meta esperada por los muchos obstáculos encontrados en el camino y a superar, incluyendo la voluntad del caminante que a menudo se doblega 
cuando las barreras surgen inesperadamente o los propios fantasmas asolan y fragilizan. Esto es el Diario de Abad, un emprender el camino, como Ulises, con un objetivo en el horizonte, formarse en un oficio, superar el reto y avanzar, pero desde el primer instante, todo y a su pesar, porque así es la vida y no la exclusiva de él, se interpone y borra el sendero a seguir, o se extravía con cantos de sirena y desvaría con otras Penélopes hasta hacerle perder el rumbo y caer en una vorágine de cuestionamientos, reproches e incertidumbres. Eso es el Diario: gritos desesperados, lamentos invocando la compasión de sí mismo y de los lectores, memoria sin escamoteos de un pasado desgarrado y de miserias morales de una sociedad que "es el único consuelo que tenemos nosotros, los hijos de este país incendiado, condenados como estamos a recordar y averiguar y lamentar, y luego a componer canciones para el incendio" (Vásquez, 2018, p. 259).

A veces Abad sale a flote cuando lee los libros y poetas amados que devienen sedante liberador, aunque a veces lo paralizan por no avizorar esa misma medida. Sin embargo, como él mismo lo reconoce, esas obras tutelares son casi siempre nutriente esencial y fecundador:

Yo no evito ni temo ser contagiado por escritores mucho mejores que yo. Al contrario, yo creo que esos contagios son fecundos. $\mathrm{Y}$ esto no tiene nada que ver con el plagio [...]. Cuando decae mi entusiasmo por lo que estoy escribiendo, leo a otros para recargarme de amor por la escritura (Bermeo Gamboa, 2020).

Pero en medio de esos devaneos por lo propio y ajeno, aflora de nuevo esa imagen fantasmática de la derrota, de su propia vulnerabilidad, de sus muchas contradicciones y ambigüedades que nunca lo han abandonado desde que, siendo un adolescente de un colegio del Opus Dei, comenzó a rebelarse contra la institucionalidad y su propio destino. Fue un lanzarse al agua sin salvavidas para quedar a la deriva. A veces lograba asirse a troncos flotantes (los libros que iba publicando con o sin certeza) que le permitían tomar nuevo aire por un momento, hasta que otra borrasca llegaba sin contemplación y lo dejaba maltrecho. Pero dejemos que él mismo exprese ese estado revelado:

Yo creo que son unos diarios muy obsesionados con la literatura, con los libros, con la lectura, con las ganas de ser escritor, con las ganas de llegar algún día a escribir algo que valga la pena, con la dificultad y el trabajo que eso implica, las dudas y el sufrimiento, detrás de un intento muy obsesivo y sincero (Aguilar Sosa, 2020). 
En otro momento vuelve sobre el asunto:

[...] a lo largo de los diarios también se puede ver que de lo que más escribo es de mis fracasos como escritor. En los diarios está el desconsuelo de lo que no funcionó. Cuando estoy escribiendo una novela y estoy bien y está saliendo, los diarios desaparecen. Los diarios son como la alcantarilla del escritor, ahí va tu insatisfacción, tu rabia, tu decepción, tu tristeza por no poder ser el escritor que quieres ser" (Martín, 2020).

Mucho más tarde reitera este sentimiento de encontrarse en una calle sin salida y al frente de una jauría de fantasmas que lo asolan sin remedio: "tal vez saqué mis diarios porque no tenía nada más. Cuadernos, papeles, apuntes, novelas empezadas. Ya había hecho uso de esos comienzos en Basura. Escribí Basura con toda mi basura”. Héctor Abad es un humano como los otros, y su oficio de escritor es su desafío y el espejo que proyecta lo que más teme. Lo que fue presente es cabal testimonio de esto. Y más que un diario, su Diario es un manifiesto de desagravios consigo mismo y con el mundo, y una lucha contra las múltiples muertes que le asedian. No en vano y con ecos de Borges, afirma: "La literatura es una lucha contra la muerte, es un intento por hacer duradero lo breve, lo caduco" (Bermeo Gamboa, 2020).

\section{Referencias bibliográficas}

Abad Faciolince, H. (2019). Lo que fue presente (Diarios 1985-2006). Bogotá: Alfaguara.

Aguilar Sosa, Y. (2020). "Llevar un diario es un ejercicio para no autoengañarse nunca": Héctor Abad Faciolince. El Universal (16 de marzo). Recuperado de: https://www.eluniversal.com.mx/cultura/llevar-un-diario-es-un-ejercicio-para-no-autoenganarse-nunca-hector-abad-faciolince [21.05.21].

Bermeo Gamboa, L. C. (2020). Desnudarse con palabras, entrevista con Héctor Abad Faciolince. Gaceta de El País: Cali (30 de agosto). Recuperado de https://www.elpais.com.co/cultura/gaceta/desnudarse-con-palabras-entrevista-con-hector-abad-faciolince.html [21.05.21].

Martín, I. (2020). Héctor Abad Faciolince: "Hay que acordarse de olvidar". ABC Cultura (8 de marzo).

Recuperado de https://www.abc.es/cultura/libros/abci-hector-abad-faciolince-acordarse-olvidar-202003080116 noticia.html [21.05.21].

Miłosz, C. (1990). De la Baltique au Pacifique. Paris: Fayard.

Ricœur, P. (1969). Le conflit des interprétations. Essais d'herméneutique. Paris: Seuil.

Rulfo, J. (2005). El llano en llamas. Bogotá: Ediciones Montserrate.

Vásquez, J. G. (2018). Canciones para el incendio. Bogotá: Penguin Random House. 